\title{
A biogeographic map of soil bacterial communities in wheats field of the North China Plain
}

\author{
Yu Shi ${ }^{1}$, Yuntao $\mathrm{Li}^{1,2}$, Meiqing Yuan ${ }^{3}$, Jonathan M. Adams ${ }^{4}$, Xianzhang Pan ${ }^{1}$, Yunfeng Yang ${ }^{5}$, Haiyan Chu ${ }^{1, *}$ \\ 1 State Key Laboratory of Soil and Sustainable Agriculture, Institute of Soil Science, Chinese Academy of Sciences, Nanjing 210008, China \\ 2 University of Chinese Academy of Sciences, Beijing 100049, China \\ 3 Key Laboratory of Forensic Genetics of Ministry of Public Security, Institute of Forensic Science of Ministry of Public Security, Beijing \\ 100038, China \\ 4 School of Water, Energy and Environment, Cranfield University, Cranfield MK46 OAL, UK \\ 5 State Key Laboratory of Environment Simulation and Pollution Control, School of Environment, Tsinghua University, Beijing 100084, China
}

\section{ARTICLE INFO}

\section{Article history:}

Received August 30, 2018

Revised November 13, 2018

Accepted November 20, 2018

\section{Keywords:}

Predicting map

Bacteria diversity

Actinobacteria

Alphaproteobacteria

\begin{abstract}
A B S T R A C T
The vast diversity of soil bacteria provides essential ecosystem services that support agricultural production. Variation in the diversity and composition of soil biota may have predictive values for soil nutrient cycling and resilience of ecosystem services, thus providing valuable insights to improve food production. The North China Plain (NCP) is one of the world's key agricultural regions, supplying more than $50 \%$ of the cereal consumed in Asia. However, it is unknown whether soil microbial diversity is predictable across the NCP. Using the MiSeq Illumina platform, we examined bacterial community variation in relation to spatial and environmental factors from 243 soils in wheat-maize double cropping rotation fields across the $\mathrm{NCP}$, which cover nearly 0.3 million $\mathrm{km}^{2}$. Based on observed bacterial communities and their relationships with environmental factors, we generated a map of bacterial communities across the NCP. The highest bacterial diversity was found in the middle part of the NCP, with most of the variation in diversity attributable to differences in the community similarity of Actinobacteria and Alphaproteobacteria. These findings provide important baseline information for analyzing the relationships between microbial community, soil functionality and crop yields.
\end{abstract}

(C) Higher Education Press 2019

\section{Introduction}

The North China Plain (NCP) is one of China's largest plains and the political, economic and cultural center of China. Formed from the deposits of the Yellow River, it covers an area of more than $400000 \mathrm{~km}^{2}$ at heights of less than $50 \mathrm{~m}$ above sea level throughout most of its extent. This NCP is the most important food-producing region in China (Jeong et al., 2014), with wheat-maize double cropping rotation being the

\footnotetext{
* Corresponding author

E-mail address: hychu@issas.ac.cn (H. Y. Chu)
}

dominant cropping system for the past 40 years. Due to longterm intense cultivation, irrigation, fertilization and improvements in crop varieties, agricultural practices have fundamentally altered the physicochemical and microbiological characteristics of NCP soils. Soil microorganisms play a pivotal role in essential ecosystem services such as regulating soil nutrient cycling and improving crop production (Orgiazzi et al., 2016; Fierer, 2017; Delgado-Baquerizo et al., 2018), and are strongly influenced by the environments (Karimi et al., 2018; Ramirez et al., 2018). Therefore, it is essential to understand how the microbes will respond to environmental changes. Toward this end, a prerequisite is to generate a biogeographic map of soil microbial communities as baseline 
information (Whitfield, 2005), something never before attempted for cropping ecosystems.

Historically, vegetation maps have been informative for understanding how plant species are distributed (Fierer, 2017). Likewise, "Putting the microorganisms on the map," as proposed by Martiny et al. (2006), is essential for elucidating soil microbial distribution and responses to environmental conditions (Delgado-Baquerizo et al., 2018). Moreover, predicting the microbial map can help understanding the mechanisms that structure the microbial communities and informing conservation and management decisions (Ladau et al., 2013). An excellent example is to reconstruct the microbial diversity of pre-agricultural tallgrass prairie soils in the United States, which shows that small changes in soil microbial diversity might lead to important influence on ecosystem processes (Fierer et al., 2013). Using species distribution modeling, Ladau et al. (2013) mapped global distribution of bacteria in marine surface waters and found that bacterial diversity was greatest in temperate latitudes. When mapping diversity and interpolated taxonomic richness of fungi at the global scale, Tedersoo et al. (2014) found that both edaphic and spatial factors imposed strong influence on soil fungal richness and community composition. Interestingly, Barberén et al. (2015) mapped fungal and bacterial communities of indoor and outdoor dust samples, and demonstrated that human hosts played a substantial role in determining indoor bacterial communities. Together, these studies have shown that soil microbial diversity and community could be estimated in the areas where we have soil variables data but without microbial survey, which is useful for improving our knowledge of the pivotal role of soil microorganisms in biogeochemical cycling and ecological services (Martiny et al., 2006; Ladau et al., 2013).

We have shown recently that the diversity and community composition of soil bacteria are strongly influenced by soil factors such as soil $\mathrm{pH}$ and total phosphorus concentration (Shi et al., 2018). However, a comprehensive understanding of how soil microbial diversity and communities vary across this region and what factors are important in shaping the soil microbial structure are still lacking. Based on the observational soil bacterial data and soil physiochemical map of the North China Plain, we hypothesize that the soil bacterial diversity and community are predictable across this region. As the species distribution modeling (SDM) has been widely used in predicting the diversity patterns of not only macroorganisms (Franklin and Miller, 2009) but also microorganisms (Larsen et al., 2012, Fierer et al., 2013, Ladau et al., 2013), we adopt the SDM to predict soil bacterial diversity in North China Plain.

\section{Materials and methods}

\subsection{Soil sampling and sequencing}

Soil sampling and biogeochemical measurements were previously described (Shi et al., 2018). Briefly, 243 soil samples were collected from 27 sites in wheat fields (Figure $\mathrm{S} 1 \mathrm{~A})$ across North China Plain during November 20th to 30th, 2014. We sampled 9 plots (each plot is $100 \mathrm{~m} \times 100 \mathrm{~m}$ ) about $3.3 \mathrm{~km}$ apart for each site (within $100 \mathrm{~km}^{2}$ (Figure S1 B)), and collected 12 cores in each plot at a depth of $0-15 \mathrm{~cm}$ and mixed as one sample. All the samples were stored in ice boxes and shipped to the laboratory as soon as possible. DNA extraction and soil variables were described previously (Shi et al., 2018). Briefly, soil DNA was extracted with a Power Soil DNA kit (MO BIO, Carlsbad, USA), purified with an Ultra Clean 15 DNA purification kit (MO BIO), and stored at $-40^{\circ} \mathrm{C}$. Soil $\mathrm{pH}$ was measured in fresh soils, with a soil-to-water ratio of 1:5, using a pH monitor (Thermo Orion-868, Boston, USA). Soil moisture content was determined gravimetrically after ovendrying the samples at $105^{\circ} \mathrm{C}$ for $16 \mathrm{~h}$. Total $\mathrm{C}$ and $\mathrm{N}$ contents were determined by combustion (2400 II CHNS/0 Elemental I Analyzer, Perkin-Elmer, Boston, USA). Dissolved organic carbon (DOC), total dissolved nitrogen (TDN), ammonium $\left(\mathrm{NH}_{4}{ }^{+}\right)$, and nitrate $\left(\mathrm{NO}_{3}{ }^{-}\right)$contents were measured by adding $50 \mathrm{~mL}$ of $0.5 \mathrm{M} \mathrm{K}_{2} \mathrm{SO}_{4}$ to $10 \mathrm{~g}$ of fresh soil, shaking for $1 \mathrm{~h}$, and then filtering through a G4 $(1.2 \mu \mathrm{m})$ glass fiber filter (Thermo Fisher, Beijing, China). DOC and TDN contents were determined using a total organic carbon/total nitrogen analyzer (Shimadzu, Kyoto, Japan). The $\mathrm{NH}_{4}{ }^{+}$and $\mathrm{NO}_{3}{ }_{3}$ contents were assessed colorimetrically via an automated segmented flow analysis (AAlll; Bran + Luebbe, Norderstedt, Germany). Triplicates of each sample were amplified in a $50-\mu \mathrm{L}$ reaction under the following conditions: 30 cycles of denaturation at $94^{\circ} \mathrm{C}$ for $30 \mathrm{~s}$, annealing at $54^{\circ} \mathrm{C}$ for $30 \mathrm{~s}$, and extension at $72^{\circ} \mathrm{C}$ for $1 \mathrm{~min}$ with a final extension at $72^{\circ} \mathrm{C}$ for 7 $\mathrm{min}$. The triplicate PCR products for each sample were pooled for both the bacteria and fungi, purified using a QIA quick PCR purification kit (Qiagen, Hilden, Germany), and then quantified using a NanoDrop ND-1000 spectrophotometer (Thermo Scientific, Waltham, USA). Equimolar ratios of the PCR products were mixed in a single tube and sequenced on an Illumina MiSeq platform (Caporaso et al., 2012). The details in raw data processing and analyzing has been described in Shi et al. (2018). Phylogenetic diversity was calculated according to Faith (1996). To obtain phylogenetic diversity for each phylum or class, each phylum or class was extracted from the whole OTUs table and then the PD values were calculated.

\subsection{Predictive map}

All the tested soil variables which were included in the NCP shape file significantly correlated with bacterial diversity were selected to construct a general linear model. According to the SDM method (Robert et al., 2015), the linear model is recommended in order to easily interpret different weights of each variable. Then, geographical coordinates were used to obtain georeferenced variables (e.g., soil factors) from the NCP shape file. The map including corresponding soil factors $(\mathrm{pH}$, $\mathrm{OM}, \mathrm{TK}, \mathrm{AP}, \mathrm{TN}$ and TP) across the North China Plain were acquired from the soil database (http://www.soil.csdb.cn/). Then we selected the factors significantly related to the bacterial diversity and community composition. Finally, using 
species distribution modeling, a resolution of 0.03 degree map was applied to illustrate bacterial diversity distribution by inputting the background soil data into the general linear model in package dismo (Robert et al., 2015), and was plotted with ggplot2 (Wickham, 2009). Meanwhile, cross validation was conducted to verify the predictive map. The observational data were randomly divided into two parts, one included training data and the other one included test data. Subsequently, the larger part was used to reconstruct the general linear model. The soil data of the smaller part were inputted into the model and the bacterial diversity data was used to compare with the predicted diversity generated from the model. Similarly, the predictive map of bacterial community structure and the diversity of some phyla (dominant phyla) were conducted through the procedures described above. The NMDS (Nonmetric Multidimensional scaling) axis 1 value was used for bacterial community structure because the NMDS axis 1 could reflect the principle variation of the communities and had been frequently used in many studies (e.g. Barberén et al., 2015)

All GIS files were acquired through internet or other researchers (http://vdb3.soil.csdb.cn) and processed in ArcGIS 10.2.2 (http://www.esri.com/software/arcgis/arcgis-fordesktop) and $\mathrm{R}$ [package $\mathrm{sp}$ (version 1.2-3), raster (version 2.5-2), reshape2 (version 1.4.1) and rgdal (version 1.1-8)].

\section{Results}

\subsection{Selection of predictive factors}

Using the general linear modeling (GLM), soil factors that showed significant correlation with PD, NMDS, and phyla or classes were chosen to predict the map (Table 1). The phylogenetic diversity (PD) could be well predicted by soil $\mathrm{pH}$ and NMDS1 could be best explained by soil pH, TK and TP. For the dominant phyla, the predicting factors were also selected. For example, the PD value for Acidobacteria positively correlated with TP, while TN could decrease the PD value. Generally, we found most of the phyla could be predicted by soil pH and TP (Table 1).

3.2 The map of soil bacterial diversity and community composition across the North China Plain

Using species distribution modeling (SDM), we predicted the soil bacterial diversity and community composition across the North China Plain (Fig. 1), which was subjected to cross validation between predicted diversity (including phylogenetic diversity and microbial communities) and actual values. We found that the PD and NMDS were very predictable (Fig. 2; $R^{2}$ $\left.=0.6962, p<0.001 ; R^{2}=0.7908, p<0.001\right)$, and the PD predictive map was similar to the NMDS map (Fig. 1). The PD was high in the middle of NCP and low in north-east, east and south of the NCP (Fig. 1A). The central area of the NCP inhabited soil bacterial communities considerably different from those at the edges of the NCP (Fig. 1B).
3.3 The map of dominant phyla diversity across the North China Plain

The diversity and community dissimilarity patterns were mainly attributed to changes in the diversity and dissimilarity of Actinobacteria and Alphaproteobacteria, which were the dominant bacterial phyla across the collected soils (Fig. 3B and $3 \mathrm{E}$ ). In addition, Nitrospirae, which had low abundance, also presented similar pattern with the whole diversity and community dissimilarity patterns. Betaproteobacteria showed a different pattern compared to the whole bacterial diversity pattern (Fig. 3F): high diversity for the whole bacteria and low diversity for Betaproteobacteria in the middle of North China Plain. Gamma-proteobacteria also presented high PD values in the southern NCP (Fig. 3G), which were different from the whole bacterial pattern. Firmicutes showed no considerable fluctuations in abundance across the sampling area (Fig. $3 \mathrm{H}$ ). Acidobacteria, Deltaproteobacteria, Bacteroidetes, Gemmatimonadetes and Chloroflexi had similar patterns with high diversity in the central part of NCP (Fig. $3 \mathrm{~A}, 3 \mathrm{C}$ and $3 \mathrm{H}-\mathrm{J}$ ). Planctomycetes map showed similar pattern to the Alphaproteobacteria (Fig. 3D), but with a low diversity in the south part of NCP. Some other bacterial phyla diversity maps were showed in Fig. 3. Cross validation between the predicted PD values of some bacterial phyla and actual values were conducted and presented in Figure S2.

\section{Discussion}

Consistent with our hypothesis, the soil bacterial diversity and community distribution of North China Plain were predictable in terms of soil factors. The maps presented here not only help understand the types of soil bacteria in "terra incognita" (Fierer and Ladau, 2012), but also revealed factors important in shaping the microbial distribution in North China Plain. Various studies have been carried out worldwide to produce maps of crop diseases (Brooker et al., 2003; Scholte et al., 2013), but few have mapped the belowground soil microorganisms in the cropland. It is clear that soil microbes can provide tremendous benefits to the human health (Wall et al., 2015), such as preventing disease and promoting plant growth (Toju et al., 2018). Thus, the map of soil microbes of North China Plain has the potential to improve our knowledge of belowground ecology in cropland, and to save more manpower and material resource in exploring agriculturally beneficial microorganisms.

Consistent with the observed data (Shi et al., 2018), the distribution map could be well predicted by soil pH (cross validation value $R^{2}=0.6962$ ). This suggested that soil $\mathrm{pH}$ was not only a driver for the soil microbial distribution (Fierer and Jackson, 2006; Chu et al., 2010; Griffiths et al., 2011), but also could serve as a predictor for the locations with no microbial surveys in NCP wheat soils. Our findings were different from the predictive map of microbial diversity in the tallgrass prairie soils of the United States, which found that soil moisture was a strong predictor (Fierer et al., 2013). The similarity of PD and 


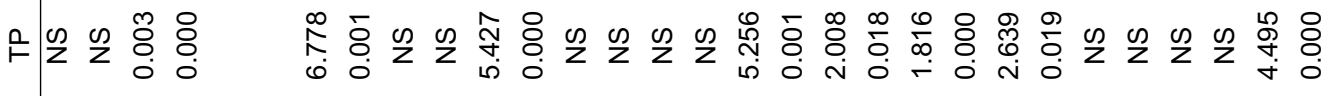

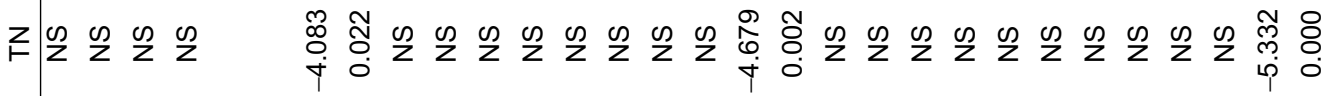

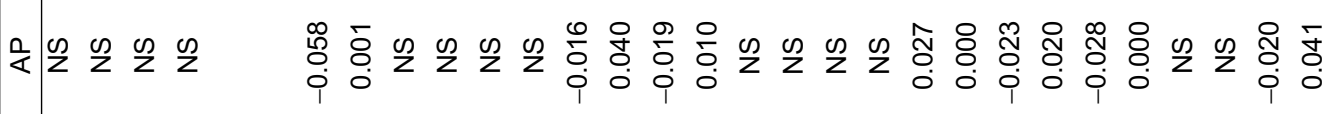

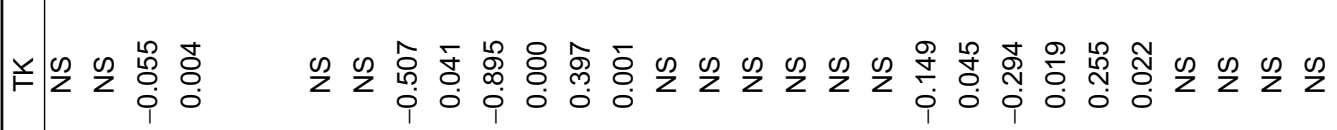

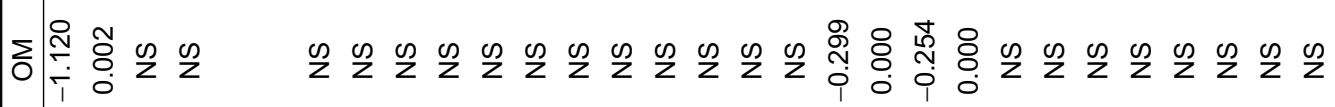

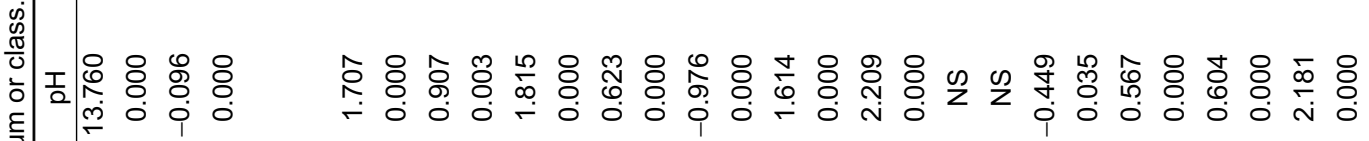

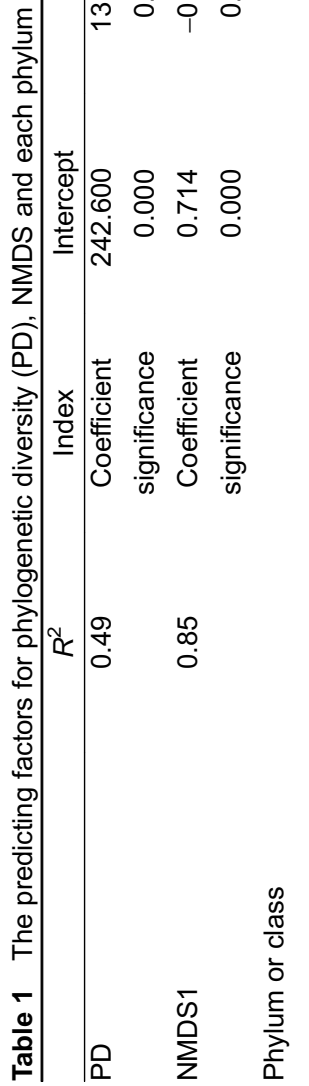
ㅊ \& 응 \&

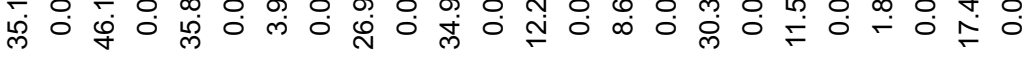

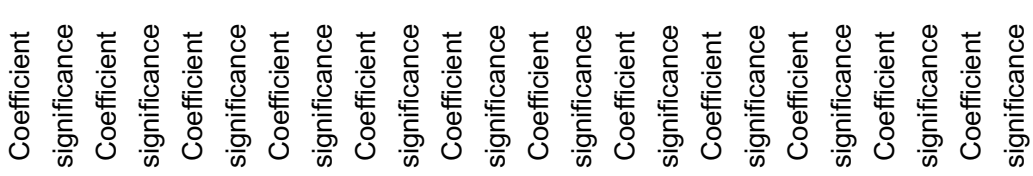
芯 

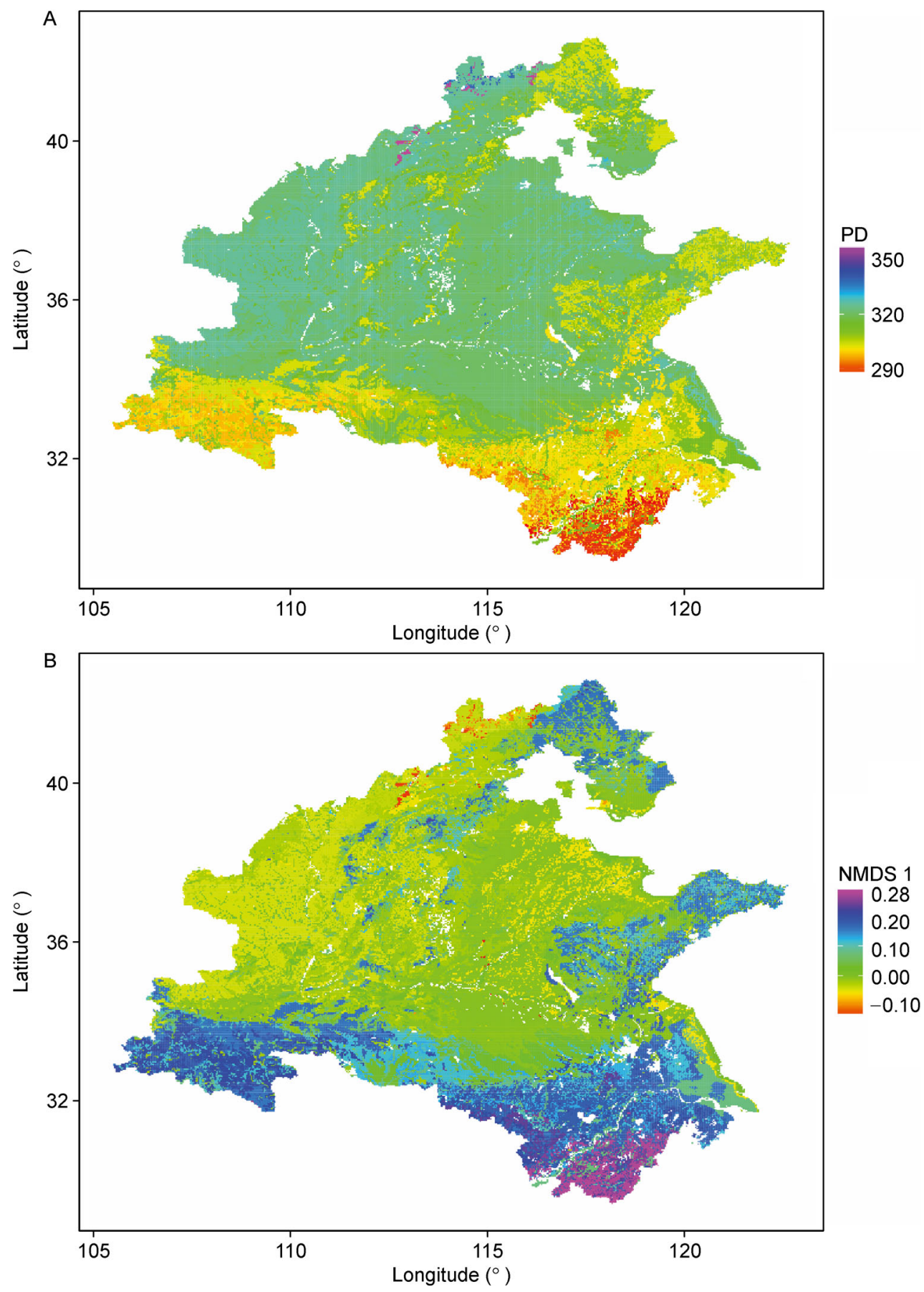

Fig. 1 Predictive maps of phylogenetic diversity (PD) (A) and NMDS values (B) for soil bacterial communities. PD and NMDS value were mapped on $100 \times 100$ grid cells.

NMDS patterns suggested there was a strong correlation between bacterial alpha- and beta-diversity, the reason might be that both diversity indices were influenced by the same soil factors such as soil $\mathrm{pH}$. Therefore, the predictive map of soil bacterial diversity and community across the NCP wheat soils not only can help in understanding the belowground diversity, but also can guide management of soil conditions and inform management strategies for improving soil health (Harris, 2009; Ladau et al., 2013), such as enhancing beneficial microbial diversity to promote nutrition supply or suppress disease (Wall et al., 2015). Additionally, this predictive approach could be used to predict the biogeographic patterns of microbial diversity in similar cropland system, and identify their shared niche spaces (similar diversity or community corresponding to similar soil conditions) and reveal the underground biogeochemical cycling (Larsen et al., 2012; Fierer et al., 2012).

In our study, the predicted maps of diversity and community 

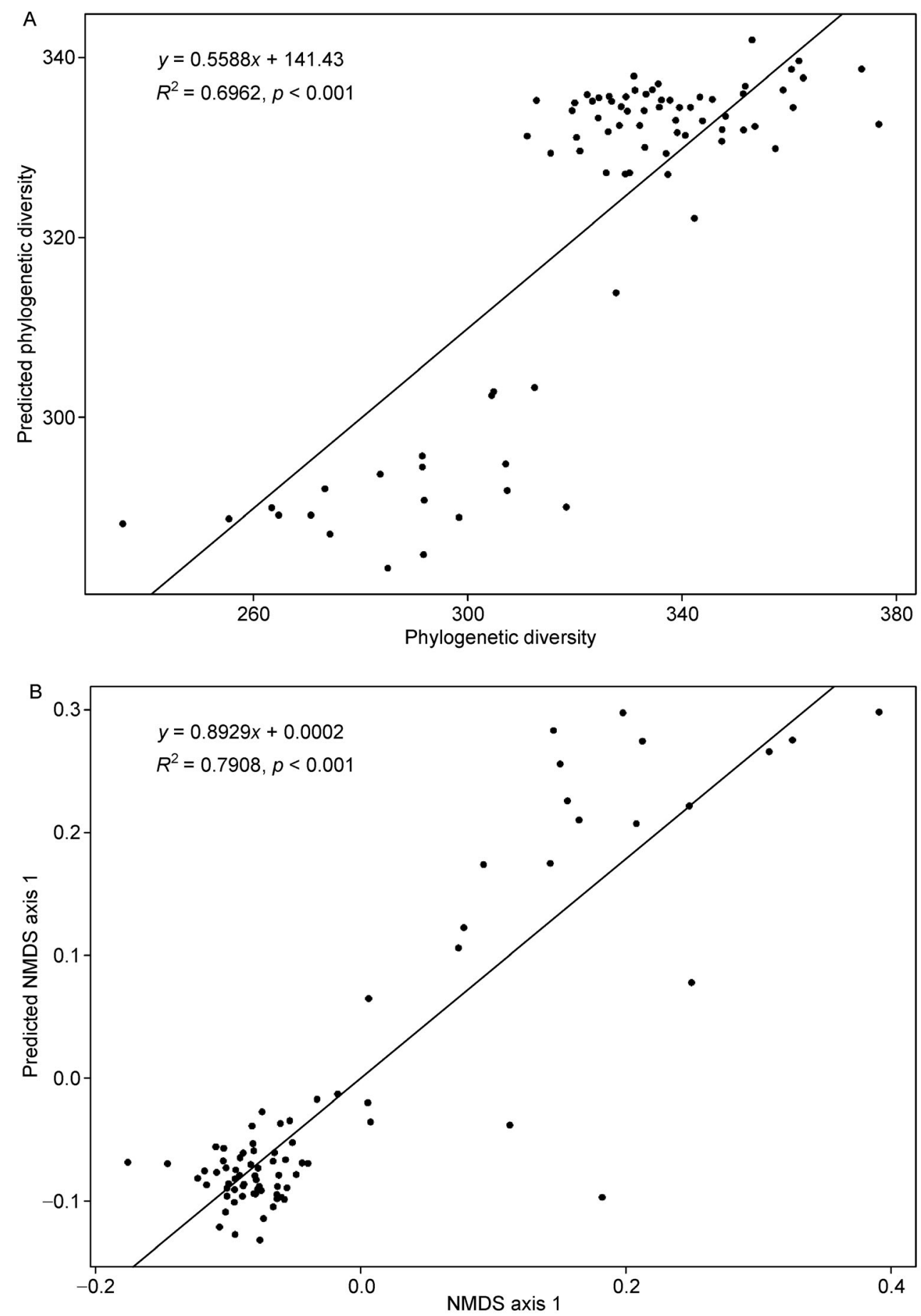

Fig. 2 Cross validation between predicted phylogenetic diversity (A), NMDS value (B) and actual phylogenetic diversity and NMDS value.

dissimilarity were mainly attributed to changes in the diversity and dissimilarity of Alphaproteobacteria and Actinobacteria (Fig. 2B and 2E). Similar to the diversity and community dissimilarity map, these two phyla were both well predicted by the soil $\mathrm{pH}$ (Table 1). Alphaproteobacteria is often the dominant bacterial taxon in soil (Delgado-Baquerizo et al., 2018). Actinobacteria are also abundant in soil communities, especially in alkaline soils, and can provide a wide variety of useful antibiotics (Bérdy, 2005; Manivasagan et al., 2013,
Zhang et al., 2014; Chu et al., 2016). Notably, Actinobacteria were described as a more promising taxon of plant growth promoting bacteria (PGPA), and a rich source of bioactive metabolites such as herbicides, fungicides and biofertilizers (Reviewed by Hamedi and Mohammadipanah, 2015). For other phyla, such as Acidobacteria, Deltaproteobacteria, Chloroflexi, Bacteroidetes and Gemmatimonadetes, the predictive maps showed similar patterns (Fig. 3). When investigating their predictors, we found that in each case the 

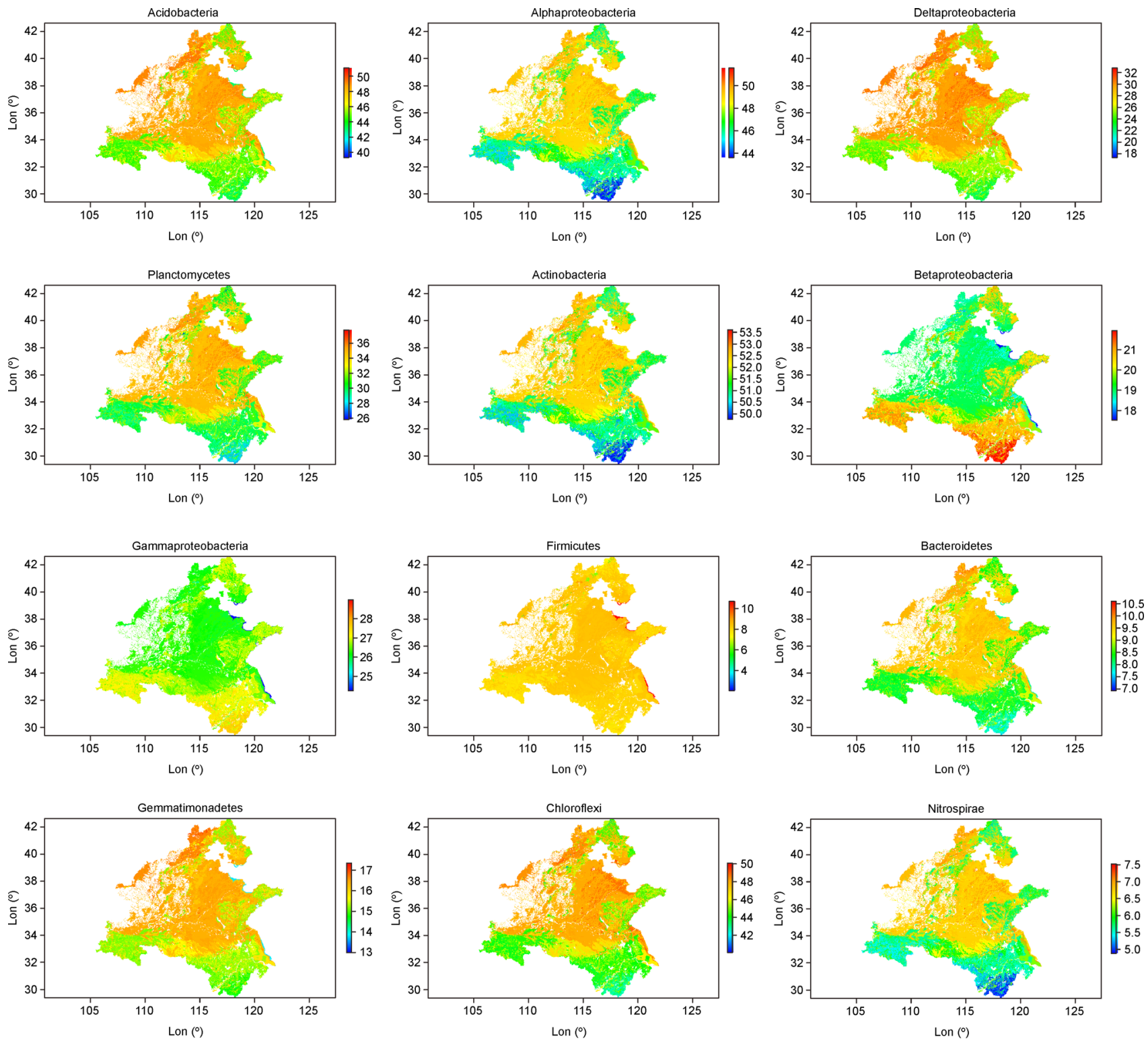

Fig. 3 Predictive maps of selected bacterial phyla (PD value).

phylogenetic diversity of these phyla increased with the soil $\mathrm{pH}$, but their phylogenetic diversity decreased with other soil chemical factors that differed from one phylum to another (Table 1). In contrast to the general phylogenetic diversity and distribution pattern of other phyla, Beta-proteobacteria and Gamma-proteobacteria had lower diversity in the middle part of North China Plain, which might be due to the negative correlation between these two phyla and soil $\mathrm{pH}$. These results suggest that it would be complicated to manage soil microorganisms, however, our predictive map provides some clues or baseline information on enhancing the soil ecosystem services through mediating soil microbes.

Considering the indications of the important role of soil microbial community composition in crop productivity (Fierer, 2017), the map of soil microorganisms could provide a means for producing healthier crops and higher food production. Compared to macro-organisms, microorganisms are widespread and have rapid reproduction rates (Poole et al., 2003), which can be either active or dormant (Hubert et al., 2009). Therefore, multiple time point sampling at a single site and predictive maps (which can accurately reflect the microbial geographic patterns) are needed in future studies.

\section{Acknowledgments}

We thank Ruibo Sun, Xingjia Xiang, Dan He, Kaoping Zhang, Yingying Ni, Teng Yang, Hongfei Wang and Kunkun Fan for their assistance in soil sampling and laboratory analyses. This work was supported by the Strategic Priority Research Program (XDB15010101) of the Chinese Academy of Sciences, the 
National Key Research and Development Program of China (2017YFD0200604, 2017YFC0803803), the "135" Plan and Frontiers Projects of Institute of Soil Science (ISSASIP1641), The collaborative innovation project from the Forensic Appraisal Center of The ministry of Public Security of the People's Republic of China (2016XTCX02), and the China Biodiversity Observation Networks (Sino BON).

\section{Electronic supplementary material}

Supplementary material is available in the online version of this article at http://dx.doi.org/10.1007/s42832-019-0014-x and is accessible for authorized users.

\section{Reference}

Barberán, A., Dunn, R.R., Reich, B.J., Pacifici, K., Laber, E.B., Menninger, H.L., Morton, J.M., Henley, J.B., Leff, J.W., Miller, S.L., Fierer, N., 2015. The ecology of microscopic life in household dust. Proceedings. Biological Sciences 282, 212-220.

Bérdy, J., 2005. Bioactive microbial metabolites. Journal of Antibiotics $58,1-26$.

Brooker, S., Singhasivanon, P., Waikagul, J., Supavej, S., Kojima, S., Takeuchi, T., Luong, T.V., Looareesuwan, S., 2003. Mapping soiltransmitted helminths in Southeast Asia and implications for parasite control. Southeast Asian Journal of Tropical Medicine and Public Health 34, 24-36.

Caporaso, J.G., Lauber, C.L., Walters, W.A., Berg-Lyons, D., Huntley, J., Fierer, N., Owens, S.M., Betley, J., Fraser, L., Bauer, M., Gormley, N., Gilbert, J.A., Smith, G., Knight, R., 2012. Ultra-highthroughput microbial community analysis on the Illumina HiSeq and MiSeq platforms. ISME Journal 6, 1621-1624.

Chu, H., Fierer, N., Lauber, C.L., Caporaso, J.G., Knight, R., Grogan, P., 2010. Soil bacterial diversity in the Arctic is not fundamentally different from that found in other biomes. Environmental Microbiology 12, 2998-3006.

Chu, H., Sun, H., Tripathi, B.M., Adams, J.M., Huang, R., Zhang, Y., Shi, Y., 2016. Bacterial community dissimilarity between the surface and subsurface soils equals horizontal differences over several kilometers in the western Tibetan Plateau. Environmental Microbiology 18, 1523-1533.

Delgado-Baquerizo, M., Oliverio, A.M., Brewer, T.E., BenaventGonzález, A., Eldridge, D.J., Bardgett, R.D., Maestre, F.T., Singh, B.K., Fierer, N., 2018. A global atlas of the dominant bacteria found in soil. Science 359, 320-325.

Faith, D.P., 1996. Conservation evaluation and phylogenetic diversity. Biological Conservation 61, 1-10.

Fierer, N., 2017. Embracing the unknown: disentangling the complexities of the soil microbiome. Nature Reviews. Microbiology 15, 579-590.

Fierer, N., Jackson, R.B., 2006. The diversity and biogeography of soil bacterial communities. Proceedings of the National Academy of Sciences of the United States of America 103, 626-631.

Fierer, N., Ladau, J., 2012. Predicting microbial distributions in space and time. Nature Methods 9, 549-551.

Fierer, N., Ladau, J., Clemente, J.C., Leff, J.W., Owens, S.M., Pollard, K.S., Knight, R., Gilbert, J.A., McCulley, R.L., 2013. Reconstructing the microbial diversity and function of pre-agricultural tallgrass prairie soils in the United States. Science 342, 621-624.

Franklin, J., Miller, J.A., 2009. Mapping species distributions: Spatial Inference and Prediction. Cambridge University Press: Cambridge, UK.

Griffiths, R.I., Thomson, B.C., James, P., Bell, T., Bailey, M., Whiteley, A.S., 2011. The bacterial biogeography of British soils. Environmental Microbiology 13, 1642-1654.

Hamedi, J., Mohammadipanah, F., 2015. Biotechnological application and taxonomical distribution of plant growth promoting actinobacteria. Journal of Industrial Microbiology \& Biotechnology 42, 157171.

Harris, J., 2009. Soil microbial communities and restoration ecology: facilitators or followers? Science 325, 573-574.

Hubert, C., Loy, A., Nickel, M., Arnosti, C., Baranyi, C., Brüchert, V., Ferdelman, T., Finster, K., Christensen, F.M., Rosa de Rezende, J., Vandieken, V., Jørgensen, B.B., 2009. A constant flux of diverse thermophilic bacteria into the cold Arctic seabed. Science 325, 1541-1544.

Jeong, S.J., Ho, C.H., Piao, S.L., Kim, J., Ciais, P., Lee, Y.B., Jhun, J. G., Park, S.K., 2014. Effects of double cropping on summer climate of the North China Plain and neighbouring regions. Nature Climate Change 4, 615-619.

Karimi, B., Terrat, S., Dequiedt, S., Saby, N.P.A., Horrigue, W., Lelièvre, M., Nowak, V., Jolivet, C., Arrouays, D., Wincker, P., Cruaud, C., Bispo, A., Maron, P.A., Bouré, N.C.P., Ranjard, L., 2018. Biogeography of soil bacteria and archaea across France. Science Advances 4, t1808.

Ladau, J., Sharpton, T.J., Finucane, M.M., Jospin, G., Kembel, S.W., O'Dwyer, J., Koeppel, A.F., Green, J.L., Pollard, K.S., 2013. Global marine bacterial diversity peaks at high latitudes in winter. ISME Journal 7, 1669-1677.

Larsen, P.E., Field, D., Gilbert, J.A., 2012. Predicting bacterial community assemblages using an artificial neural network approach. Nature Methods 9, 621-625.

Lauber, C.L., Hamady, M., Knight, R., Fierer, N., 2009. Pyrosequencing-based assessment of soil $\mathrm{pH}$ as a predictor of soil bacterial community structure at the continental scale. Applied and Environmental Microbiology 75, 5111-5120.

Manivasagan, P., Venkatesan, J., Sivakumar, K., Kim, S.K., 2013. RETRACTED: Marine actinobacterial metabolites: current status and future perspectives. Microbiology Research 168, 311-332.

Martiny, J.B.H., Bohannan, B.J.M., Brown, J.H., Colwell, R.K., Fuhrman, J.A., Green, J.L., Horner-Devine, M.C., Kane, M., Krumins, J.A., Kuske, C.R., Morin, P.J., Naeem, S., Ovreås, L., Reysenbach, A.L., Smith, V.H., Staley, J.T., 2006. Microbial biogeography: putting microorganisms on the map. Nature Reviews. Microbiology 4, 102-112.

Orgiazzi, A., Bardgett, R.D., Barrios, E., Behan-Pelletier, V., Briones, M.J.I., Chotte, J.L., 2016, Global Soil Biodiversity Atlas. European Commission, Publications Office of the European Union, Luxembourg. 176 pp.

Poole, A.M., Phillips, M.J., Penny, D., 2003. Prokaryote and eukaryote 
evolvability. Bio Systems 69, 163-185.

$\mathrm{R}$ Development Core Team, 2006. R, a language and environment for statistical computing. R Foundation for Statistical Computing, Vienna, Austria.

Ramirez, K.S., Knight, C.G., de Hollander, M., Brearley, F.Q., Constantinides, B., Cotton, A., Creer, S., Crowther, T.W., Davison, J., Delgado-Baquerizo, M., Dorrepaal, E., Elliott, D.R., Fox, G., Griffiths, R.I., Hale, C., Hartman, K., Houlden, A., Jones, D.L., Krab, E.J., Maestre, F.T., McGuire, K.L., Monteux, S., Orr, C.H., van der Putten, W.H., Roberts, I.S., Robinson, D.A., Rocca, J.D., Rowntree, J., Schlaeppi, K., Shepherd, M., Singh, B.K., Straathof, A.L., Bhatnagar, J.M., Thion, C., van der Heijden, M.G.A., de Vries, F.T., 2018. Detecting macroecological patterns in bacterial communities across independent studies of global soils. Nature Microbiology 3, 189-196.

Robert, J.H., Steven, P., John, L., Jane, E., 2015. Species Distribution Modeling. dismo: Species Distribution Modeling. R package version 1.0-12. http://CRAN.R-project.org/package = dismo.

Scholte, R.G., Schur, N., Bavia, M.E., Carvalho, E.M., Chammartin, F., Utzinger, J., Vounatsou, P., 2013. Spatial analysis and risk mapping of soil-transmitted helminth infections in Brazil, using Bayesian geostatistical models. Geospatial Health 8, 97-110.

Shi, Y., Li, Y.T., Xiang, X.J., Sun, R.B., Yang, T., He, D., Zhang, K.P., Ni, Y.Y., Zhu, Y.G., Adams, J.M., Chu, H.Y., 2018. Spatial scale affects the relative role of stochasticity versus determinism in soil bacterial communities in wheat fields across the North China Plain. Microbiome 6, 27.

Tedersoo, L., Bahram, M., Põlme, S., Kõljalg, U., Yorou, N.S.,
Wijesundera, R., Villarreal Ruiz, L., Vasco-Palacios, A.M., Thu, P. Q., Suija, A., Smith, M.E., Sharp, C., Saluveer, E., Saitta, A., Rosas, M., Riit, T., Ratkowsky, D., Pritsch, K., Põldmaa, K., Piepenbring, M., Phosri, C., Peterson, M., Parts, K., Pärtel, K., Otsing, E., Nouhra, E., Njouonkou, A.L., Nilsson, R.H., Morgado, L.N., Mayor, J., May, T.W., Majuakim, L., Lodge, D.J., Lee, S.S., Larsson, K.H., Kohout, P., Hosaka, K., Hiiesalu, I., Henkel, T.W., Harend, H., Guo, L.D., Greslebin, A., Grelet, G., Geml, J., Gates, G., Dunstan, W., Dunk, C., Drenkhan, R., Dearnaley, J., De Kesel, A., Dang, T., Chen, X., Buegger, F., Brearley, F.Q., Bonito, G., Anslan, S., Abell, S., Abarenkov, K., 2014. Fungal biogeography. Global diversity and geography of soil fungi. Science 346, 1256688.

Toju, H., Peay, K.G., Yamamichi, M., Narisawa, K., Hiruma, K., Naito, K., Fukuda, S., Ushio, M., Nakaoka, S., Onoda, Y., Yoshida, K., Schlaeppi, K., Bai, Y., Sugiura, R., Ichihashi, Y., Minamisawa, K., Kiers, E.T., 2018. Core microbiomes for sustainable agroecosystems. Nature Plants 4, 247-257.

Wall, D.H., Nielsen, U.N., Six, J., 2015. Soil biodiversity and human health. Nature 528, 69-76.

Whitfield, J., 2005. Biogeography. Is everything everywhere? Science 310, 960-961.

Wickham, H., 2009. ggplot2: elegant graphics for data analysis. Springer New York.

Zhang, X., Xu, S., Li, C., Zhao, L., Feng, H., Yue, G., Ren, Z., Cheng, G., 2014. The soil carbon/nitrogen ratio and moisture affect microbial community structures in alkaline permafrost-affected soils with different vegetation types on the Tibetan plateau. Research in Microbiology 165, 128-139. 